\title{
KARAKTERISTIK BERPIKIR KREATIF SISWA KELAS VII SMP N 1 KRAGAN DALAM MEMECAHKAN DAN MENGAJUKAN MASALAH MATEMATIKA MATERI PERBANDINGAN DITINJAU DARI GAYA KOGNITIF
}

\author{
Dian Fitri Argarini ${ }^{1}$, Budiyono $^{2}$, Imam Sujadi $^{3}$ \\ ${ }^{1,2,3}$ Program Magister Pendidikan Matematika, PPs Universitas Sebelas Maret Surakarta
}

\begin{abstract}
The research objectives were to determine and to describe creative thinking characteristic of $7^{\text {th }}$ grade students of SMP N 1 Kragan in solving and proposing problem at comparative case seen from the cognitive style. This research belonged to descriptive research by qualitative-explorative approach. The sample was taken by purposive sampling technique. The subjects being used in this research were 4 , those were 2 students with field dependent cognitive style and 2 students with field independent cognitive style. The subject grouping based on cognitive style was taken by group embedded figures test. There were two instruments that were used to collect the data of this research. The first instrument was solving and proposing problem test instrument. The second was interview guidance. They were validated by using the time triangulation test and the reference fulfillment. The data were analyzed using a Miles and Huberman's concept, that was data reduction, presentation, and conclusion.. The results of this research show as follows, (1) Creative thinking characteristics of students who had field dependent cognitive style in solving and proposing problem were as follows. The fluency aspect was shown by the students through 4 stages of creative thinking process, both in solving and proposing the problem. The four stages were preparation stage, incubation stage, illumination stage, and verification stage. The flexibility aspect in solving problems appeared when the students gave the other alternative answer, whereas this aspect was not fulfilled in proposing the problems. The originality aspect was not fulfilled in solving and proposing problems. (2) Creative thinking characteristics of students who had field independent cognitive style in solving and proposing problem were as follows. The fluency aspect was shown by the students through 4 stages of creative thinking process, both in solving and proposing the problem. The four stages were preparation stage, incubation stage, illumination stage, and verification stage. The flexibility aspect in solving problems was shown when the students gave the other alternative answer, while in proposing the problem this aspect was not completed because students were able to make only one question. The originality aspect in solving the problem could be seen when the students gave a new way solution and this was different from the previous one. Meanwhile in proposing the problems, aspet of originality was not fulfilled.
\end{abstract}

Keywords: creative thinking characteristics, solving problems, proposing problems, cognitive style

\section{PENDAHULUAN}

Matematika merupakan cabang ilmu pengetahuan eksak dan terorganisir secara sistematik. Sama halnya dengan ilmu yang lain, matematika juga memiliki aspek terapan atau praktik. Matematika juga memiliki peranan penting sebagai wadah peserta didik untuk memiliki kemampuan berpikir analitis, evaluatif, dan argumentatif. Manusia sering kali dihadapkan dengan berbagai masalah kehidupan yang harus diselesaikan. Masalah dalam pembelajaran matematika sering disajikan dalam bentuk soal matematika. Herman Hudojo (2005) menyatakan bahwa, suatu soal matematika akan menjadi masalah bagi 
siswa jika soal yang diberikan dapat dimengerti oleh siswa, namun soal tersebut harus merupakan tantangan bagi siswa untuk menjawabnya, dan soal tersebut tidak dapat dijawab dengan prosedur rutin yang telah diketahui siswa.

Pada suatu proses pemecahan suatu masalah, terjadi proses berpikir sehingga individu dapat menemukan jawaban yang diinginkan. Herman Hudojo (2005) menyatakan bahwa dengan pemecahan masalah individu akan berlatih memproses data atau informasi. Pemrosesan data atau informasi itu disebut berpikir. Pemecahan merupakan hal yang sangat dasar dalam pembelajaran matematika, Rays (dalam Zhu, 2007) menyatakan "problem solving is the foundation of much mathematical activity". Pehkonen (1997: 64) menyatakan bahwa pemecahan masalah memiliki manfaat yaitu: (1) mengembangkan keterampilan kognitif, (2) mendorong kreativitas, (3) pemecahan masalah merupakan bagian dari proses aplikasi matematika, dan (4) memotivasi siswa untuk belajar matematika. Selain pemecahan masalah (problem solving), hal lain yang sering menjadi kendala adalah ketika siswa tidak berani atau tidak bisa mengajukan masalah (problem posing). Problem posing adalah kegiatan perumusan soal atau masalah oleh peserta didik. Peserta didik hanya diberikan situasi tertentu sebagai stimulus dalam merumuskan soal atau masalah.

Kreativitas dalam pemecahan dan pengajuan masalah merupakan kemampuankemampuan yang dituntut oleh dunia kerja saat ini. Menurut Career Center Maine Department of Labor (2001), beberapa karakteristik individu yang dikehendaki dunia kerja adalah: (1) mempunyai kepercayaan diri, (2) mempunyai motivasi untuk berprestasi, (3) menguasai keterampilan-keterampilan dasar seperti membaca, menulis, mendengarkan, berbicara, dan melek komputer (computer literacy), (4) menguasai keterampilan berpikir, seperti memecahkan masalah (problem solving), membuat soal (problem posing), mengambil keputusan (decision making), berpikir analitis (analythical thinking), dan berpikir kreatif (creative thinking), dan (5) menguasai keterampilan interpersonal, seperti kemampuan berkerja dalam tim dan melakukan negosiasi. Maka, bisa disimpulkan bahwa kreativitas, pemecahan masalah (problem solving), dan pengajuan masalah (problem posing) sangat berkaitan erat dan saling mempengaruhi.

Silver (1997) menjelaskan hubungan kreativitas dengan pengajuan dan pemecahan masalah. Berdasarkan observasi yang telah dilakukannya, hubungan kreativitas tidak hanya pada pengajuan masalah sendiri tetapi merupakan hubungan antara pemecahan masalah dan pengajuan masalah. Keduanya nanti dapat menentukan sebuah tingkat kreativitas dengan jelas. Dengan demikian, untuk melihat kemampuan atau tingkat berpikir kreatif siswa tidak cukup dari pengajuan atau pemecahan masalah saja, tetapi gabungan antara pemecahan dan pengajuan masalah. Masalah dalam penelitian yang dimaksud adalah soal cerita yang tidak 
rutin dengan solusi tidak tunggal. Hal ini senada dengan apa yang diungkapkan oleh Stigler dan Hiebert (dalam Waynberg dan Leikin, 2006: 57) yang menyatakan bahwa "multiple solutions to problems increased the quality of mathematcal lesson". Jawaban beragam dari suatu masalah meningkatkan kualitas pembelajaran matematika. Pernyataan tersebut diperkuat oleh Leikin dan Waynberg (dalam Bingolbali, 2011: 18) yang menyatakan bahwa "solving problem in multiple ways contributes to the development of students' creativity and critical thinking”. Pemecahan masalah dengan cara yang berbeda memberikan kontribusi terhadap perkembangan kreativitas dan berpikir kritis siswa. Hal ini menggambarkan bahwa keterampilan berpikir kreatif memungkinkan seorang individu memandang suatu masalah dari berbagai perspektif sehingga memungkinkannya untuk menemukan solusi kreatif dari masalah yang diselesaikan. Proses berpikir kreatif sendiri meliputi empat tahap yaitu: (1) Tahap persiapan (preparation), siswa mempersiapkan diri untuk memecahkan masalah dengan cara mengumpulkan data yang relevan. (2) Tahap inkubasi (Incubation), merupakan tahap dimana siswa mengolah pengetahuan lama yang dimiliki untuk memperoleh solusi penyelesaian dari masalah yang didapatkan. (3) Tahap iluminasi (Illumination), siswa mendapatkan sebuah pemecahan masalah yang diikuti dengan munculnya inspirasi dan ide-ide yang mengawali dan mengikuti munculnya inspirasi dan gagasan baru. (4) Tahap verifikasi (Verification), siswa menguji dan memeriksa pemecahan masalah tersebut terhadap realitas. Diperlukan pemikiran kritis dan konvergen, siswa saat melakukan tahap verifikasi.

Silver (1997: 76) menyebutkan bahwa ada tiga karakteristik berpikir kreatif. Ketiga karakteristik tersebut yaitu: (1) kelancaran (fluency), mengacu pada sejumlah besar ide, gagasan, atau alternatif dalam memecahkan persoalan. Kelancaran menyiratkan pemahaman, tidak hanya mengingat sesuatu yang dipelajari. (2) keluwesan (flexibility), mengacu pada produksi gagasan yang menunjukkan berbagai kemungkinan. Keluwesan melibatkan kemampuan untuk melihat berbagai hal dari sudut pandang yang berbeda serta menggunakan banyak strategi atau pendekatan yang berbeda. (3) kebaruan (originality), mengacu pada solusi yang berbeda dalam suatu kelompok atau sesuatu yang baru atau belum pernah ada sebelumnya.

Tatag Yuli Eko Siswono (2005: 1) menyatakan bahwa kreativitas merupakan satu hal yang jarang sekali diperhatikan dalam pembelajaran matematika. Guru biasanya menempatkan logika sebagai titik incar pembicaraan dan menganggap kreativitas merupakan hal yang tidak penting dalam pembelajaran matematika. Salah satu faktor yang mempengaruhi kreativitas seorang individu adalah gaya kognitif. Balchin dan Jackson (2009) menyatakan bahwa: 
Cognitive and learning styles can be used to predict what kind of teaching approaches would be most effective for an individual or group. This short piece focuses on cognitive styles that might be useful to consider when designing teaching for creativity.

Ferrari dan Stenberg (Mahadi Saputro, 2011: 27) menyatakan "cognitive style refer to dominant or typical ways children use their cognitive abilities across a wide range of situations, when the situation is complex enough to allow a variety of responses". Park (1996: 639) menyatakan bahwa gaya kognitif merupakan karakteristik individu dalam berpikir, merasakan, mengingat, memecahkan masalah, dan membuat keputusan. Dari berbagai pendapat ahli tersebut, maka gaya kognitif adalah cara dominan atau khusus anak menggunakan kemampuan kognitif mereka di berbagai situasi, ketika menghadapi situai yang rumit memungkinkan timbulnya berbagai tanggapan.

Gaya kognitif merupakan karakteristik individu dalam berpikir, merasakan, mengingat, memecahkan masalah dan membuat keputusan. Sebagai karakteristik perilaku, gaya kognitif berada pada lintasan kecerdasan dan kepribadian. Gaya kognitif menunjukkan adanya variasi antar individu dalam menyelesaikan suatu tugas, tetapi variasi itu tidak menunjukkan tingkat intelegensi atau kemampuan tertentu. Karakteristik individu yang memiliki gaya kognitif yang sama belum tentu memiliki kemampuan yang sama, apalagi individu yang memiliki gaya kognitif berbeda, kecenderungan perbedaan kemampuan akan menjadi lebih besar. Riding dan Eugene (1997) dalam penelitiannya menyatakan bahwa:

The accommodation of cognitive style in the training design process has the potential to improve the efficiency and effectiveness of individual lerarning, and may also help in the identification of learning difficulties. A recognition of the strengths and weakness of one's own style naturally leads to the formation of strategies (coping behaviours).

Penggunaan gaya kognitif dalam pelatihan kontruksi proses memiliki potensi untuk meningkatkan keefisiensi dan keefektifan seseorang dalam belajar, dan mungkin juga dalam mengindikasi kesulitan belajar. Pengenalan kelebihan dan kelemahan gaya seseorang biasanya bisa menuntun pada bentuk strategi atau peniruan sikap.

Ketentuan penilaian dalam GEFT dengan memberi skor 1 untuk setiap butir soal yang dijawab siswa dengan benar, dengan memberi skor 0 jika jawaban salah. Jika siswa yang tidak dapat memecahkan sesuai waktu yang ditetapkan tiap tahapan, maka soal dianggap salah dan diberi skor 0. Dengan demikian, total skor yang diperoleh siswa dalam rentang 0 sampai 18. Maka penggolongan gaya kognitifnya adalah, siswa yang memperoleh skor 0 - 9 tergolong siswa dengan gaya kognitif field dependent, dan siswa yang memperoleh skor $10-18$ tergolong siswa dengan gaya kognitif field independent.

Beberapa karaktersitik individu yang memiliki gaya kognitf field dependent sudah diidentifikasikan oleh Witkin (1977:8-14), antara lain cenderung untuk berpikir 
global, cenderung menerima struktur yang sudah ada, memiliki orientasi sosial, cenderung memilih profesi yang menekankan pada ketrampilan sosial, cenderung mengikuti tujuan yang yang sudah ada, dan cenderung bekerja dengan motivasi eksternal serta lebih tertarik pada penguatan eksternal. Individu field dependent cenderung menggunakan pendekatan pasif dalam belajar. Tujuan pembelajaran cenderung diikuti apa adanya, sehingga diperlukan tujuan pembelajaran yang tersusun dengan baik. Struktur materi pembelajaran juga cenderung diikuti sesuai yang disajikan, sehingga diperlukan materi pembelajaran yang terstruktur dengan baik dan sistematis. Pengalaman individu field dependent terintegrasi dan cenderung lebih holistik (Keefe, 1987: 17). Akibatnya individu field dependent kurang memiliki ketrampilan merestrukturisasi kognitif. Proses pembelajaran serial lebih menguntungkan bagi individu field dependent (Brame dan Wickens, 2000:3). Bimbingan tambahan dari guru dalam belajar menjadikan individu field dependent berhasil lebih baik (Mrosla, 1988:165). Bimbingan tambahan berupa penjelasan lebih rinci disertai ilustrasi selama penyajian, dilengkapi pemberian contoh yang bervariasi akan meningkatkan pemahaman materi.

Sedangkan, individu field independent pada proses belajar cenderung berinteraksi dengan guru seperlunya saja. Mengikuti tujuan pembelajaran yang sudah ada dan dinyatakan secara eksternal kurang menarik bagi mereka karena cenderung merumuskan sendiri tujuan pembelajaran yang dinyatakan secara internal. Karakteristik yang dimiliki individu field independent berimplikasi pada aktivitasnya selama mengikuti proses pembelajaran (Witkin, dkk., 1977: 17-36), antara lain yaitu: (1) cenderung untuk merumuskan sendiri tujuan pembelajaran. (2) lebih tertarik pada penguatan internal dan motivasi intrinsik. (3) cenderung untuk menggunakan struktur perantara dalam mempelajari materi.Selain itu proses pembelajaran yang berlangsung secara paralel lebih menguntungkan bagi individu field independent (Brame dan Wickens, 2000: 3). Model pembelajaran yang memberi kesempatan kepada siswa untuk belajar secara mandiri memberi kesempatan kepada individu field independent untuk bisa berhasil lebih lebih baik (Mrosla, 1988: 165). Selain itu proses pembelajaran yang berlangsung secara paralel lebih menguntungkan bagi individu field independent (Brame dan Wickens, 2000: 3). Pembelajaran secara paralel memberi peluang beberapa kegiatan pembelajaran dilakukan sekaligus dalam satu waktu.

Penelitian ini bermaksud untuk mendeskripsikan karakteristik berpikir kreatif siswa kelas VII Sekolah Menengah Pertama yang memiliki gaya kognitif field dependent (FI) dan field independent (FI) dalam memecahkan dan mengajukan masalah materi perbandingan. 


\section{METODE PENELITIAN}

Jenis penelitian ini adalah penelitian deskriptif dengan pendekatan kualitatifeksploratif. Pengelompokan subjek berdasarkan gaya kognitif ini dilakukan dengan tes Group Embedded Figures Test (GEFT). Instrumen yang digunakan untuk mengumpulkan data pada penelitian ini ada dua jenis, instrumen pertama adalah istrumen tes pemecahan dan pengajuan masalah, instrumen kedua adalah pedoman wawancara. Uji validasi data yang digunakan dalam peneltian ini adalah uji triangulasi waktu.. Data yang dianalisis adalah hasil tes pemecahan dan pengajuan masalah materi perbandingan dan hasil wawancara untuk mendeskripsikan karakteristik berpikir kreatif siswa dalam memecahkan dan mengajukan masalah. Pengambilan sampel dengan teknik purposive sampling. Subjek yang digunakan dalam penelitian ini sebanyak empat subjek penelitian, yaitu 2 orang siswa dengan gaya kognitif field dependent (FD) dan 2 orang siswa dengan gaya kognitif field independent (FI).

Karakteristik berpikir kreatif pada penelitian kali ini mengacu pada karakteristik yang dikemukakan oleh Silver, yaitu aspek kelancaran (fluency), aspek keluwesan (flexibility), dan kebaruan (originality). Adapun indikator pemecahan masalah dan pengajuan masalah dalam berpikir kreatif sebagai berikut.

Tabel 1. Hubungan aspek-aspek kreativitas dalam pemecahan dan pengajuan masalah

\begin{tabular}{|c|c|c|}
\hline Pemecahan Masalah & $\begin{array}{c}\text { Aspek } \\
\text { Kreativitas }\end{array}$ & Pengajuan Masalah \\
\hline $\begin{array}{l}\text { Siswa menyelesaikan masalah } \\
\text { dengan pemahaman yang benar } \\
\text { bukan sekedar ingatan dan hafalan } \\
\text { berdasarkan proses berpikir kreatif }\end{array}$ & Kelancaran & $\begin{array}{l}\text { Siswa mampu membuat } \\
\text { masalah yang dapat } \\
\text { dipecahkan, melalui proses } \\
\text { berpikir kreatif. }\end{array}$ \\
\hline $\begin{array}{l}\text { Siswa menyelesaikan masalah } \\
\text { dengan satu cara lalu dengan cara } \\
\text { lain. Mampu memberikan beragam } \\
\text { jawaban dengan benar }\end{array}$ & Keluwesan & $\begin{array}{l}\text { Siswa mampu menyusun } \\
\text { sebuah masalah dari berbagai } \\
\text { macam sudut pandang, atau } \\
\text { siswa mampu menyusun } \\
\text { masalah lebih dari satu. }\end{array}$ \\
\hline $\begin{array}{l}\text { Siswa memeriksa jawaban dengan } \\
\text { sebuah metode penyelesaian lalu } \\
\text { membuat metode penyelesaian lain } \\
\text { yang baru dan berbeda }\end{array}$ & Kebaruan & $\begin{array}{l}\text { Siswa memeriksa beberapa } \\
\text { masalah yang diajukan } \\
\text { kemudian mengajukan suatu } \\
\text { masalah yang berbeda }\end{array}$ \\
\hline
\end{tabular}

Analisis data yang dilakukan, yaitu pengumpulan data, penyajian data, reduksi data, dan penarikan kesimpulan (Sugiyono, 2008).

\section{HASIL PENELITIAN DAN PEMBAHASAN}

Berdasarkan pada aspek-aspek karakteristik berpikir kreatif dalam memecahkan dan mengajukan masalah menurut Tatag Yuli pada Tabel 1, penelitian ini menunjukkan 
bahwa setiap subjek yang diambil tidak dapat memenuhi seluruh aspek karakteristik berpikir kreatif dalam memecahkan masalah dan mengajukan masalah. Aspek- aspek kreatifitas tersebut terdiri dari kelancaran (fluency), keluwesan (flexibility), dan kebaruan (originality). Rangkuman hasil analisis karakteristik berpikir kreatif dalam memecahkan dan mengajukan masalah lebih lengkap masing-masing akan dijelaskan sebagai berikut.

1. Kelompok Gaya Kognitif Field Dependent (FD)

Berdasarkan analisis yang telah dilakukan pada subjek gaya kognitif FD, yaitu $\mathrm{CU}$ dan FAP diperoleh hasil rincian karakteristik berpikir kreatif dalam memecahkan dan mengajukan masalah. Pada pembahasan ini, hanya akan dibahas karakteristik berpikir kreatif subjek FAP, hal ini dikarenakan subjek FAP lebih banyak memenuhi aspek-aspek karakteristik berpikir kreatif tersebut jika dibandingkan dengan subjek CU.

Aspek kelancaran (fluency) subjek FAP dalam memecahkan masalah terlihat dari proses berpikir kreatif. Tahap yang pertama yaitu tahap persiapan (preparation), pada tahap ini subjek mampu menjelaskan hal-hal yang diketahui dan ditanyakan dari soal yang didapat. Hal in mengindikasikan bahwa subjek mampu mengumpulkan data yang relevan yang akan digunakan dalam menyelesaikan masalah. Selanjutnya adalah tahap inkubasi (incubation), FAP pada tahap ini mampu memberikan ide awal untuk memberikan penyelesaian masalah, ide tersebut adalah pembuatan denah untuk membantu dalam menyelesaikan masalah. Meskipun denah yang dibuat oleh subjek belum tepat sepenuhnya. Tahap selanjutnya adalah tahap iluminasi (illumination), pada tahap ini subjek FAP memberikan penyelesaian masalah dengan cara coba-coba (trial error). Tahap terakhir adalah verifikasi (verification), tahap ini menunjukkan bahwa subjek mengoreksi apakah penyelesian yang dilakukan sudah benar, untuk mengecek jawaban terssebut benar atau salah subjek mengembalikan paa syarat pembagian ruangan dan luas tanah yang disediakan dalam soal. Keempat tahap ini bisa dipenuhi subjek FAP dengan baik.

Hal yang sama juga terjadi pada pengajuan masalah, subjek FAP mampu memenuhi keempat tahap tersebut. Dimulai dari persiapan, hal ini ditunjukkan dengan kemampuan FAP dalam memahami perintah dari soal yang diperoleh. Kemudian dilanjutkan tahap inkubasi dimana ide awal subjek dimulai dengan membuat denah ruangan yang diminta pada soal. Tahap selanjutnya yaitu iluminasi, dimana subjek mampu menyampaikan hal-hal yang diketahu dari soal yang dibuat sendiri dan syaratsyarat pembagian ruangan serta penyusunan kalimat pertanyaan yang tepat. Terakhir adalah tahap verifikasi, tahap ini mengecek apakah soal yang dibuat sudah tepat atau 
belum. Cara subjek mengecek adalah dengan membuat penyelesaian soal yang dibuat sendiri.

Aspek keluwesan pada pemecahan masalah ditunjukkan dengan subjek FAP mampu memberikan alternatif jawaban yang lain, subjek mampu memberikan pembagian luas ruangan lebih dari satu dan dapat mengindikasi adanya keluwesan dalam pemecahan masalah yang diberikan. Pada pengajuan masalah, subjek hanya mampu membuat satu buah soal terkait materi perbandingan, dan tidak bisa memenuhi indikator aspek keluwesan yang diminta dalam penelitian.

Aspek kebaruan subjek FD dalam memecahkan dan mengajukan masalah tidak bisa dipenuhi. Pada pemecahan masalah subjek tidak mampu memberikan cara penyelesaian yang baru atau berbeda dari penyelesaian yang telah dilakukan sebelumnya. Hal serupa juga terdapat dalam pengajuan masalah, subjek membuat soal yang sejenis dengan soal yang sebelumnya telah diberikan, dan tidak mampu membuat jenis soal yang berbeda dari sebelumnya.

Hasil penelitian ini didukung oleh penelitian terdahulu yang dilakukan oleh Dona Dinda Pratiwi (2013), yang menyatakan bahwa siswa dengan gaya kognitif field dependent menyatakan pemecahan masalah dengan terpola namun masih bersifat umum, merespon secara lisan dengan baik namun masih bersifat umum. Hasil ini mengindikasikan bahwa siswa dengan field dependent dalam melakukan proses berpikir masih bergantung dengan pedoman dan sesuai dengan apa yang disajikan yang akan mempengaruhi kreativitas siswa. Hal ini diperkuat dengan pernyataan dari Mrosla (1988) yang menyebutkan bimbingan tambahan dari guru dalam belajar menjadikan individu field dependent berhasil lebih baik. Pembelajaran yang lebih menekankan ketergantungan terhadap pedoman yang diberikan bisa mengakibatkan keterbatasan siswa dalam mengembangkan diri dan kreativitas. Dari hasil wawancara siswa lebih banyak menunggu pertanyaan dari peneliti. Selain itu, siswa fiel dependent kurang dalam hal mengeksplor sesuatu yang baru. Hal ini terlihat dari aspek keluwesan dan kebaruan yang masih belum terlihat jelas pada proses berpikir siswa field dependent. Hasil ini serupa dengan pendapat Keefe (1987) yang menyatakan bahwa individu field dependent terintegrasi dan cenderunglebih holistik yang berakibat individu field dependent kurang memiliki keterampilan merestruksi kognitf.

2. Kelompok Gaya Kognitif Field Independent (FI)

Berdasarkan analisis yang telah dilakukan pada subjek gaya kognitif FI, yaitu LD dan RRS diperoleh hasil rincian karakteristik berpikir kreatif dalam memecahkan dan mengajukan masalah. Pada pembahasan ini, hanya akan dibahas karakteristik berpikir 
kreatif subjek RRS, hal ini dikarenakan subjek RRS lebih banyak memenuhi aspekaspek karakteristik berpikir kreatif tersebut jika dibandingkan dengan subjek LD.

Aspek kelancaran (fluency) subjek RRS dalam memecahkan masalah terlihat dari proses berpikir kreatif. Tahap yang pertama yaitu tahap persiapan (preparation), pada tahap ini subjek mampu menjelaskan hal-hal yang diketahui dan ditanyakan dari soal yang didapat. Hal ini mengindikasikan bahwa subjek mampu mengumpulkan data yang relevan yang akan digunakan dalam menyelesaikan masalah. Selanjutnya adalah tahap inkubasi (incubation), pada tahap inkubasi RRS mampu memberikan ide awal untuk memberikan penyelesaian masalah, ide tersebut adalah pembuatan denah untuk membantu dalam menyelesaikan masalah. Meskipun denah yang dibuat oleh subjek belum tepat sepenuhnya. Tahap selanjutnya adalah tahap iluminasi (illumination), pada tahap ini subjek RRS memberikan penyelesaian masalah dengan cara coba-coba (trial error). Tahap terakhir adalah verifikasi (verification), tahap ini menunjukkan bahwa subjek mengoreksi apakah penyelesian yang dilakukan sudah benar, untuk mengecek jawaban terssebut benar atau salah subjek mengembalikan paa syarat pembagian ruangan dan luas tanah yang disediakan dalam soal. Subjek RRS memenuhi seluruh tahap pada aspek kelancaran dalam memecahkan masalah.

Hal yang sama juga terjadi pada pengajuan masalah, subjek RRS mampu memenuhi keempat tahap tersebut. Dimulai dari persiapan, hal ini ditunjukkan dengan kemampuan RRS dalam memahami perintah dari soal yang diperoleh. Kemudian dilanjutkan tahap inkubasi dimana ide awal subjek dimulai dengan membuat denah ruangan yang diminta pada soal. Tahap selanjutnya yaitu iluminasi, dimana subjek mampu menyampaikan hal-hal yang diketahu dari soal yang dibuat sendiri dan syaratsyarat pembagian ruangan serta penyusunan kalimat pertanyaan yang tepat. Terakhir adalah tahap verifikasi, tahap ini mengecek apakah soal yang dibuat sudah tepat atau belum. Cara subjek mengecek adalah dengan membuat penyelesaian soal yang dibuat sendiri.

Indikator aspek keluwesan dalam pemecahan masalah dipenuhi oleh subjek RRS, yaitu subjek mampu memberikan pembagian luas ruang lain yang berarti subjek mampu memberikan alternatif jawaban lebih dari satu. Sedangkan, pada pengajuan masalah, subjek hanya mampu membuat satu buah soal terkait materi perbandingan, dan tidak bisa memenuhi indikator aspek keluwesan yang diminta dalam penelitian yaitu membuat masalah atau soal lebih dari satu.

Subjek RRS memiliki aspek kebaruan dalam pemecahan masalah karena mampu memenuhi indikator dari aspek originality yang diminta dalam penelitian. Kebaruan dalam pemecahan masalah ditunjukkan subjek dengan memberikan cara penyelesaian 
yang berbeda dari cara yang diberikan subjek sebelumnya. Sedangkan pada pengajuan masalah subjek belum mampu memberikan jenis soal yang berbeda dari yang dibuat siswa sebelumnya. Soal yang dibuat siswa, masih terkesan sama dengan soal yang diberikan dan dipecahkan dalam penelitian.

Hasil penelitian ini didukung oleh penelitian terdahulu yang dilakukan oleh Dona Dinda Pratiwi (2013), yang menyatakan bahwa siswa dengan gaya kognitif field independent dalam menyatakan langkah pemecahan masalah dengan menganalsis permasalahan yang sebenarnya, mampu memberikan respon secara lisan dengan jelas. Hal ini diperkuat dengan pernyataan dari Mrosla (1988) yang menyebutkan model pembelajaran yang memberi kesempatan kepada siswa untuk belajar secara mandiri memberi kesempatan kepada individu field independent untuk bisa berhasil lebih lebih baik. Alasannya, selain cenderung bekerja mandiri mereka juga cenderung untuk belajar dan memberikan respon dengan motivasi intrinsik.

\section{SIMPULAN DAN SARAN}

Berdasarkan analisis data dari penelitian yang dilakukan, dapat disimpulkan sebagai berikut: (1) Karakteristik berpikir kreatif siswa kelompok gaya kognitif fiel dependent dalam memecahkan dan mengajukan masalah pada aspek kelancaran (fluency), aspek keluwesan (flexibility), dan aspek kebaruan (originality) adalah sebagai berkut. Aspek kelancaran ditunjukkan siswa melalui empat tahap proses berpikir kreatif baik dalam memecahkan maupun mengajukan masalah, empat tahap tersebut adalah tahap persiapan, tahap inkubasi, tahap iluminasi, dan tahap verifikasi. Aspek keluwesan dalam memecahkan masalah ditunjukkan siswa dengan memberikan alternatif jawaban yang lain, sedangkan pada pengajuan masalah aspek keluwesan tidak terpenuhi. Aspek kebaruan dalam memecahkan dan mengajukan masalah tidak terpenuhi (2) Karakteristik berpikir kreatif siswa kelompok gaya kognitif field independent dalam memecahkan dan mengajukan masalah pada aspek kelancaran (fluency), aspek keluwesan (flexibility), dan aspek kebaruan (originality) aadalah sebagai berikut. Aspek kelancaran ditunjukkan siswa melalui empat tahap proses berpikir kreatif baik dalam memecahkan maupun mengajukan masalah, empat tahap tersebut adalah tahap persiapan, tahap inkubasi, tahap iluminasi, dan tahap verifikasi.. Aspek keluwesan dalam memecahkan masalah ditunjukkan siswa dengan memberikan alternatif jawaban yang lain, sedangkan pada pengajuan masalah aspek keluwesan tidak terpenuhi karena siswa hanya mampu membuat satu buah soal.Aspek kebaruan dalam memecahkan masalah ditunjukkan siswa dengan memberikan jenis cara penyelesaian yang baru dan berbeda dari sebelumnya, sedangkan pada pengajuan masalah aspek kebaruan tidak terpenuhi. 
Adapun saran yang bisa disampaikan oleh peneliti antara lain yaitu: (1) pembelajaran matematika yang menekankan berpikir kreatis sebaiknya lebih ditingkatkan lagi dalam pelaksanaan. Bukan hanya berpikir kreatif dalam memecahakan masalah saja, namun juga dalam mengajukan masalah. Membiasakan siswa membuat soal dan bertanya bisa menjadi alternatif latihan siswa mengajukan masalah. (2) pemberian masalah dan soal yang variatif sebaiknya juga sering dilakukan guru pada saat pembelajaran. Hal ini bisa merangsang siswa lebih berpikir kreatif dan memiliki pengalaman dalam menyelesaikan berbagai bentuk permasalahan matematika. (3) Untuk guru dan para peneliti diharapkan penelitian ini digunakan sebagai pertimbangan untuk mengembangan penelitian lanjutan yang berkaitan dengan karakteristik berpikir kreatif, khususnya pada pemecahan masalah dan pengajuan masalah matematika berdasarkan aspek-aspek berpikir kreatif yang ditinjau dari gaya kognitif field dependent (FD) dan field independent (FI). (4) untuk siswa SMP, diharapkan melatih kemampuan matematika dalam memecahkan dan mengajukan masalah matematika dalam rangka peningkatan berpikir kreatif.

\section{DAFTAR PUSTAKA}

Balchin, T. dan Jackson, N. 2009. Developing Students' Creativity: Importance of Creativity Styles. Diunduh dari http://78.158.56.101/archive/palatine/files/1002.pdf pada 15 Januari 2014 pukul 23:11 WIB.

Bingolbali, E. 2011. Multiple Solutions to Problems in Mathematics Teaching: Do Teachers Really Value Them?. Australian Journal of Teacher Education. 36 (1).

Braune, R. dan Wickens, C. D. 2000. "Time-sharing Revisited: Test of a Componential Model for Assesment of Individual Differences," dikutip langsung oleh Yuliang Liu dan Dean Ginther, "Cognitive Styles and Distance Education,"http:// www.westgaedu/ distance/liu23.html

Career Center Maine Departmeny of Labor. (2001). Today's Work Comepetence in Maine. Diunduh dari http://mainegov-images.informe.org/labor/lmis/pdf/ EssentialWorkCompetencies

Herman Hudojo. 2005. Pengembangan Kurikulum dan Pembelajaran Matematika. Malang: Universitas Negeri Malang.

Keefe, J. W. 1987. Learning Style: Theory \& Practice. Reston: National Association of Secondary School Pricipals.

Mahadi Saputro. 2011. Analisis Kemampuan Pemecahan Masalah Matematika Berdasarkan Langkah-Lngkah Polya Ditinjau dari Gaya Kognitif Siswa. Tesis. Surakarta: UNS. Tidak Dipublikasikan.

Mrosla, H. P.1988. Field-Dependent and Field-Independent Learning Teaching Style. Contributed Papers on Improving University Teaching, Fourteenth International Conference. Umea, Sweden.

Park, O. C.1996. Adaptive Instructional Systems Handbook of Research for Educational Communications and Technology. ed. David H. Jonassen, New York: Simon \& Schuster Macmillan. 
Pehkonen, E. 1997. The State of Art in Mathematical Creativity. http://www.fiz.karlsruhe.de/fiz/publications/zdm. ZDM, 29 (3), 43.

Riding, R. J. dan Smith, E. S. 1997. Cognitive Style and Learning Strategies: Some Implications for Training Design. International Journal of Training and Development, 1 (3), 206.

Silver, E.A. 1997. Fostering Creativity Through Instruction Rich In Mathematical Problem Solving and Problem Posing. Zentralbaltt fur Didaktic der Mathematic (ZDM) - The International Journal on Mathematic Education, 29 (3), $75-80$.

Sugiyono. 2008. Memahami Penelitian Kualitatif. Bandung : Alfabeta

Tatag Yuli Eko Siswono.2005. Upaya Meningkatkan Kemampuan Berpikir Kreatif Siswa Melalui Pengajuan Masalah. Jurnal Matematika dan Sains. Program Studi Pendidikan Matematika FMIPA Universitas Negeri Yogyakarta, 10 (1), 1-9.

Waynberg, A. L. dan Leikin, R. 2006. Solving problems in Different Ways: Teachers' Knowledge Situated in Practice. Proceedings 30th Conference of the International Group for the Psychology of Mathematics Education. Vol. 4, pp. 57-64. Prague: PME

Witkin, H. A., Moore, C. A, Goodenough, D.R., dan Cox, P.W. 1977. Field Dependent and Field Independent Cognitive Style and Their ducational Implications. Reviews of Educational Research 47. Pp.1-64.

Zhu, Z. 2007. Gender Difference in Mathematical Problem Solving Patterns: A Review of Literature. International Education Journal, Shannon Research Press, 8 (2), 187-203. 